\title{
Work, Passion, Exploitation
}

\section{Jan Ch. Karlsson}

Department of Working Life Science, Karlstad University, Sweden

\begin{abstract}
This article revolves around the concepts work, passion, and exploitation. I suggest answers to three questions: What is work? What is passion? What is exploitation? Finally, I discuss some possible relations between them.
\end{abstract}

\section{KEYWORDS}

Working life / passion in work / exploitation in work

Meet three concepts: work, exploitation and passion. They all have a long history, but the combination of them varies. Work and exploitation go a long way back together in analyses of social relations of work, for example in the expression 'exploitative work forms'. Work and passion too have been connected to each other since hundreds of years, and have had a recent comeback as a conceptual pair: Today companies overbid each other to portray themselves as passionate about what they sell. Passion and exploitation, finally, have seldom been interconnected. In the following I make an exposé over these three concepts and at the end I suggest what might happen conceptually if we combine them.

\section{Work}

-here is no room for any detailed discussion about the concept of work here, but I will try to sketch in broad outline the reasoning that I have suggested in former writings (Karlsson, 2004, 2013). When I review the international social science debate about definitions of 'work,' it seems to me that there are a number of contradictory conceptual principles, which constitute boundary lines in the argumentation. I start with indicating these and then I present (at least parts of) my suggestion for getting past these contradictions.

A first dividing line goes between having a subjective or objective basis for the definition. In the first case, there are several suggestions, for example that the perspective of the worker of what work is should be guiding what is to be regarded as work in social science, or the worker's attitude to, experience, or sentiments of the activity in question. Usually, negative circumstances are emphasized, such as the worker not regarding the activity as an end in itself or not finding pleasure in it (e.g., Marshall, 1907:65); often the worker has to regard the activity as downright disagreeable, strenuous, or painful if it is to be counted as work. In the second case, the definition is built on circumstances that are independent of people's understandings (e.g., Daniels, 1987). Two common types of such definitions are that some activities, for example, child care and cleaning or wage labor, respectively, always are work.

Note: This is an expanded version of a paper earlier published in Swedish (Karlsson, 2011). 
A second dividing line runs between those who advocate a single or several concepts of work, respectively. Most social scientists appear-in spite of other differences-to have a common tendency, although the argumentation sometimes is not explicitly stated in that way: A single concept of work is enough for studies of working life. There are very few attempts to systematically build a more comprehensive set of concepts of work.

A third dividing line runs between regarding work as a number of activities per se or as the activities performed within the field of certain social relations. In the first case, the activities of work tend to be seen as historical constants that apply to all members of a given society; these activities are work whenever and wherever they occur and within any social relation (e.g., Wadel, 1979). In the second case, an activity that is work during a certain historical period or in connection with a certain social category can be non-work during another period or in connection with a different social category-it all depends on the social relations (Dubin, 1965:54). If we want to analyze work, we can in the first case go directly looking for the enumerated activities; in the second case, we first have to find the specified social relations. To return to a couple of earlier examples: Child care is often pointed out as an activity that is always worthy of being regarded as work, independent of if it is performed on the labor market or at home, during Antiquity or modern capitalism, among upper class or lower class. At the same time, all activities performed within the social relation of wage labor are almost always regarded as work, independent of if they are performed in India or China of today or Britain or Sweden of yesterday, among blue collar or white collar workers.

Finally, there is a fourth dividing line that goes between those who conduct an ontologically or an empirically based line of argument about the concept of work. Somewhat simplified we can say that the first one usually deals with the position of work in the life of human beings as species and for her development and survival (e.g., Kosík, 1976), while the other one builds on the factual manifestations they have in concrete social contexts (e.g., Applebaum, 1984).

There are, then, a number of lines of debate and theoretical contradictions and I will sketch my line of reasoning concerning each of them, as well as how these answers are related to each other. Concerning subjectively or objectively based definitions, the reasoning builds on the idea that a definition is not an end in itself but that it should ground the possibility of performing fruitful empirical studies. Definitions tell us what kinds of things there are in the world so that they can be studied. One can call this a claim on operationalism. If we tie the definition of work to a specific subjective condition-a certain cultural attitude, a specific emotion, and so on-we have (literally per definition) excluded many possibilities of empirically investigating cultural attitudes of or emotions connected to work. If a certain emotion-for example aversion-is made part of the definition of work, many possibilities of empirically studying work and emotions are blocked. I therefore propose an objectively grounded definition of the concept of work.

Concerning the question of one or several concepts of work, I rather want to transgress than choose side in this contradiction. I regard it as an unnecessary debate, the problem of which can be dissolved through a simple ranking as social science needs both: An overriding concept delimiting an approximate field as work and under that a whole set of concepts that delineate different social forms of work. Taking this stance has effects for the argumentation about the two remaining contradictions, that is activities versus social relations and ontologically versus empirically based definition. Both can be transgressed with one and the same line of reasoning: A fruitful social science definition of work should start with an ontological delimitation that can cover all types of society 
and all social contexts. My suggestion is the formulation 'the doing of human beings in the sphere of necessity' (cf. Kosík, 1976)—or simply that we work when what we do is based on an external necessity to which we must submit in order to secure our existence. For social science, this formulation about the sphere of necessity can, however, only be the point of departure, not the definitive definition. The sphere of necessity is organized in many ways in different types of society and social contexts. The ontological concept of work identifies an approximately delimited field for social scientific analysis, but we also need a whole set of concepts-'sub-definitions' of work-in order to cover the social variations of work. The basis for these definitions is the social organization of the sphere of necessity at any given time in any given social context. Each one of these definitions specifies an unambiguous and specific work form-in our type of society, for example, traditional wage labor, career wage labor, self-employment, and household work.

\section{Passion}

To get a first perspective on the concept of 'passion,' we can relate the term to some other emotions (Tab. I) based on the idea that passion is an intense and positive feeling (cf. Cardon et al., 2009:515). Intense feelings can also be negative, for example, in the form of anger or even wrath. Less intense or neutral feelings can likewise be positive and negative, respectively. In the first case, we feel content, perhaps equanimity; in the second case, we feel resignation or submissiveness.

It seems to me to be impossible to reflect on the phenomenon of passion without thinking of Charles Fourier-at least outside the religious sphere, which I exclude from the present argumentation. Fourier: French utopian socialist, who to my mind has written most inspiringly about passion. On the whole, commentators seem to agree with Johan Asplund's (1979:172) words that he was 'stark staring mad.' A dictionary of utopias characterizes the one presented by Fourier as 'one of the most imaginative and lunatic utopias in this dictionary' (Parker et al., 2007:102). Still, he is often praised as immensely interesting to read. Eric Hobsbawm (2011:32) has, for example, said that he is 'the only utopian socialist writer who can still be read today with the same sense of pleasure, illumination—and exasperation—as in the early 1840s,' and Asplund (1979:176) regards Fourier as 'a most remarkable author.' I too think that it is-at least at times-rewarding to read his works. It is a verbose and, I must admit, sometimes incomprehensible authorship, of which I here only discuss parts of his theory about passions (1966-1968, 1968 [1851]).

The human race is liberated when passion is liberated-that is a fundamental idea in Fourier. Fully developed and expressed passions lead to social fellowship, to harmony. At the same time, this harmony is built on rivalry, competition, opposition, and conflicts. If a certain passion is obstructed in society, it takes other ways, which has negative, often catastrophic consequences for individuals and the whole society. 'Every restrained passion produces its opposite, its contra-passion, which is as detrimental as natural passion

Table I Passion, anger, contentment, and resignation

\begin{tabular}{lll}
\hline & Positive feeling & Negative feeling \\
\hline Intense feeling & Passion & Anger, wrath \\
\hline Neutral feeling & Contentment, equanimity & Resignation, submissiveness \\
\hline
\end{tabular}


would have been beneficial,' he says (1966-1968:VII:390). Such a repression of passions exists in the present civilization, leading to their turning into subversive ones. Thereby, the passions have a 'double form' (1968:I:224) and Fourier's mission is to propagate for a society in which the passions become harmonious. He devotes himself to outlining how a future society in which passions flower should be organized.

Fourier was a studious classifier and his theory about passions is in principle infinite, as the passions will develop to a limitless manifoldness when they have been released from the straitjacket that civilization has forced upon them. In spite of his mania for complete classifications, he restricts himself to three main types and some variants of each (Tab. II). When the passions can flower, they will together lead to a new human and social community, a new society: Harmony. The passive passions are directed toward pleasure and it is through our senses we can experience pleasure. The five types of passive passions are, however, not positioned at the same level. For social community, the passions of taste and touch are the most important ones-which is why Fourier uses so much space to describe and analyze passions in meals and love. The active, sometimes called social, passions deal with relations between people, in which love and ambition are more important for social development than friendship and the family or parental passion. Three passions aim at organizing - and thereby the organizing of pleasure passions and social passions. They have been discovered by Fourier in spite of their constantly being repressed in civilization-and he would certainly say that they are still repressed today. (I will return to them soon.)

To Fourier, working life is to bear the stamp of desire because life is a drawn-out torment for those who have to perform work that is not pleasurable. His ambition is that work, which under civilization is nothing but suffering, shall be united with passion. This is of course an incomprehensible idea in civilization, but in Harmony, everybody will 'have a passion for work, through the love of work itself' (1968:I:278). The precondition is that each and everyone's work is an expression of individual combinations of passions. Fourier has a special liking for drastic examples and this is one of them (1966-1968:X.132-134): The Roman emperor Nero has a reputation for being unusually cruel and tyrannous. He was born with a combination of passions, which resulted in him being driven by a strong thirst for blood. If he had lived in the future society of Harmony, this would have been noticed already in his tender years and he would have been guided to become a butcher, not emperor. In this way, he would have lived a life with pleasure-filled and passionate work, which eventually would have developed him into making new scientific discoveries within agronomics. And, society would have been spared a tyrant.

Table II Fourier's typology of passions

\begin{tabular}{|c|c|c|c|}
\hline $\begin{array}{l}\text { Passive passions } \\
\text { (directed toward pleasure): }\end{array}$ & $\begin{array}{l}\text { Active passions } \\
\text { (directed toward social community): }\end{array}$ & $\begin{array}{l}\text { Neutral passions } \\
\text { (directed toward organizing): }\end{array}$ & \\
\hline $\begin{array}{l}\text { - Sight } \\
\text { - Hearing } \\
\text { - Taste } \\
\text { - Smell } \\
\text { - Touch }\end{array}$ & $\begin{array}{l}\text { - Friendship } \\
\text { - Ambition } \\
\text { - Love } \\
\text { - Family feeling }\end{array}$ & $\begin{aligned} \text { - Principle of competition } \\
\\
\text { (cabaliste) } \\
\text { - Principle of variety } \\
\quad \text { (papillon) } \\
\text { - Principle of combination } \\
\quad \text { (composite) }\end{aligned}$ & Harmony \\
\hline
\end{tabular}


Passionate work must be arranged and planned to be pleasure-filled and here the three organizing passions come into play-the three that are not being allowed to appear in civilization. The soul requires constant changes and contrasts in the same way as the butterfly (papillon) flutters from flower to flower. If the variety passion is not allowed to develop, instead being inhibited as in work under civilization, weariness, and apathy ensues. People need change already after a couple of hours, and in Harmony, no work task will be longer than that. Instead, every individual will take part in many different tasks during a working day. Here, the combination passion (composite) enters the picture (1966-1968:X:98):

Let us carefully notice this difference between the combined work order of the new society and the divided one of civilization. In the latter, an individual performs 20 tasks which are associated with a specific work. In the former, he performs one, and only one, task in 20 different types of work and chooses the working operation which he likes best and discards the other 19 if they fill him with distaste. The group members who perform these work tasks become the dearer to him, as they cooperate in this manner in order to make it possible for him to devote himself to the work he likes. This work would, however, be obnoxious to him if he had to carry out the other 19 working operations, for which he only feels disgust.

When these passions may flower, they drag along passive as well as active passions. For social scientists, the most interesting part is perhaps how they relate to the social passions. Fourier emphasizes that they have an integrating effect. As each individual partake in a lot of different activities during a day, many social ties are established that has a socially integrating effect. Asplund (1979:203) formulates in his insightful analysis what he calls Fourier's paradox, saying: 'Inconstancy produces concord.'

Work is organized in groups, based on different passions. These groups are further connected into a series, and thereby each series is to contain at least three groups to make it possible to establish two groups who compete with each other (cabaliste) and one group acting as intermediary. The passion of rivalry is the driving force for the development of community. Series have to be composited by groups, not individuals, as it is only in groups that 'harmonic rivalry' can emerge. Here is an example concerning three persons' taste passion when it comes to bread: A likes lightly salted bread, B wants a bit more salt, and $\mathrm{C}$ heavily salted bread. This, however, does not provide enough intrigues and rivalry for a well-functioning series to be organized. But, Fourier says (1966-1968:III:21):

If one instead of three counts with thirty one could imagine the following arrangement: Eight with the taste A, ten with B, twelve with C, and then they would make up a series of passion or a combination of groups that were graded and contrasted with each other when it comes to the type of bread they prefer. This will give rise to everyone having views on each other's work and this disunity will furnish the machinations which are needed for the baking of the bread and the growing of the crops to be performed with the greatest care and that the finished bread thus will be of the most outstanding quality.

But this is not enough-the series should also hook on to each other (1966-1968:III:23; emphasis removed):

The passions should be in a state of opposition to each other; they should compete, be filled with devotion and intervene in each other. A series that does not fulfil these conditions would not function as a harmonious mechanism. 
And many different passions have to be roused to make it possible for every individual to be part of many passion groups and passion series, which in its turn helps to make even more passions emerge. When all this has been developed to a sufficient degree, the passion harmony is reached-and Fourier sometimes talks about the inhabitants of the future society as Harmonians. When work is organized in accordance with harmonious passion principles, it will not only get the character of recreation, but it will also even become a feast. Work becomes a passion.

While waiting for a world organized according to our passions, we have perhaps to be content with the modest thought that work should at least be dignified (Bolton, 2007). Meanwhile, the most common topic in social science analyses of work and passion is entrepreneurship (e.g., Cardon et al., 2009). Among occupational groups that are mentioned as passionate are musicians (Brodsky, 2006) and professional football players (Bertrand, 2009). More ordinary employees are brought up in management literature, in which employer dreams of development of characteristics of workers that are supposed to enhance productivity, which has gone from work satisfaction over engagement in work to passion for work. The dream of passion comprises further that it should be a measurable personality trait in order to make it possible to hire people who already have a passion for work (Gubman, 2004).

At the same time, there is a certain parallel between Fourier's idea of the two sides of passion and modern psychological research on passions. According to Fourier's analysis, they can be given full expression or be repressed, be harmonious, or subversive, and in psychology, there is a similar distinction between on the one hand harmonious passion and on the other hand obsessive passion (Houlfort \& Vallerand, 2006; Vallerand et al., 2003). The concept passion is defined as (Vallerand et al., 2003:757)

a strong inclination toward an activity that people like, that they find important, and in which they invest time and energy. Thus, for an activity to represent passion for people, it has to be significant in their lives, something that they like, and something at which they spend time on a regular basis.

But then a distinction is thus made between two types of passion. The basis of this duality is the way in which the passion is internalized into the individual's identity. Harmonious passions are a result of an autonomous internalization of the activity in question. Individuals voluntarily form the opinion that it is important for them, which creates a motivation to devote themselves to it in a controlled way. The result is that the activity does not come into conflict with other aspects of the identity of the individuals, other parts of life or that they exclusively devote themselves to the passion. Instead, it becomes a positive influence in their lives. (It is another matter that peoples' harmonious passion still can lead to conflicts with their social milieu.) But an activity that is a passion can also become obsessive. This is when individuals internalize the passion as a result of external pressure. Engaging in the activity thereby becomes uncontrollable for the individuals. Even if they love the activity, it controls them-not the other way around. Addiction to gambling and workaholism are examples. One can say that the individuals control the harmonious passion but are controlled by the obsessive passion.

Passion is not, despite employer dreams, so much about that there are passionate and non-passionate people, respectively, as passion is related to some phenomenon- 
passion is passion for something. This was evident in the definition I just cited, but a somewhat more precise formulation is this one (Cardon et al., 2009:517): 'consciously accessible, intense positive feelings experienced by engagement in entrepreneurial activities associated with roles that are meaningful and salient to the self-identity.' I hasten to add that we can keep the other parts of the definition but change the passion of the entrepreneur to that of whomever else: professional football players, musicians, welders, nurses, stamp collectors, scientists, and so on. Other parts of the formulation too might require some comments. 'Consciously accessible': Those who are passionate experience the emotion on a conscious level and can reflect upon it and for example compare it with other feelings, which means taking position against the more romantic view that interprets passions as putting all reason out of play. 'Intense positive feelings': I commented on those in the introduction to this article. 'Engagement in activities': This means that passion is not a general or universal feeling, it has an object, it is directed toward a particular activity. 'Roles that are meaningful and salient to the self-identity [of the passionate individual]': Individuals can have several identities arranged in a hierarchy, which is connected to different roles. Passions are related to those identities that are positioned at the top of the hierarchy and therefore crucial for identity.

Altogether, this means that a passion is a protracted phenomenon, not a quickly flaring up and as rapidly disappearing emotion. One could say that passions are tenacious.

Basically, I concur with the definition of Cardon et al, but it should also be observed that it has the weakness that it, like the larger part of the literature as such, tends to provide passion with only positive traits. Let us not forget the doubleness of passions that Fourier points out and Vallerand et al. emphasize on passions also having a negative side: There are not only harmony passions but also obsession or subversive passions.

\section{Exploitation}

The third concept is exploitation. Let us start with trying to narrow down this field, which is really controversial and difficult to capture (Nielsen \& Ware, 1997), through a preliminary definition. I take the following argumentation from Tommie Shelby's (2002) basic review of the concept. The person or group X exploits the person or group Y if (2002:393):

“( $a) Y$ is forced to make a sacrifice which results in benefit for $X$; and

(b) X obtains this benefit by means of an advantage in power that $X$ has over $Y . "$

The exploiters $\mathrm{X}$ receive their advantage through the exploited $\mathrm{Y}$ sacrificing themselves and these sacrifices provide $\mathrm{X}$ with something valuable. X's advantage can be anything that improves a person's or group's well-being and welfare, but in working life, it probably mostly concerns economic exploitation. The relation is asymmetrical in that $\mathrm{X}$ exploits $\mathrm{Y}$ at the same time as $\mathrm{Y}$ does not exploit $\mathrm{X}$. This is founded on $\mathrm{X}$ having power over $\mathrm{Y}$ and that this power is used to carry through the exploitation. The argument thereby rests on Max Weber's (1978:53) definition of power: 'the probability that one actor within a social relationship will be in a position to carry out his own will despite 
resistance.' Of course, Y does not always resist; Y can, for example, regard resistance as futile and therefore yield to being exploited. Further, the exploited can sometimes have advantages of being part of the relation with X. An example: Later, I will classify wage labor as an exploitative form of work with the employer as exploiter and the employee as exploited. But in most cases, it is more advantageous for the employee to be part of the exploiting relation than being outside it and thereby be unemployed. Still, we should keep in mind that Y's sacrifice is not voluntary but comes from coercion. This coercion can not only be physical as in slavery or serfdom but also structural through all alternatives being worse for the majority of the population-the coercion of wage labor.

In this first formulation, exploitation can be such relatively simple things as a robbery of a person or the relation of a pimp to a prostitute, but what is more interesting in the present context are more protracted social exploitative relations. They concern what Shelby calls self-reproducing exploitative relationships, which he defines in this way (2002:404-405):

“(a) $Y$ is regularly forced to make sacrifices that result in benefits for $X$;

(b) $X$ obtains these benefits by means of an advantage in power that $X$ has over $Y$;

and

(c) As a result of $(a)$ and $(b)$, perhaps in combination with other factors, $X$ 's power advantage over $Y$ is maintained (or is increased) and $Y$ remains in the condition of being forced to make sacrifices for X's benefit."

A reiteration, a regularity over time, has now been introduced in (a) and the result is that (a) and (b) together lead to the possibility of the exploiting structure being reproduced (c).

If we look at analyses of exploitation toward this background, a dividing line seems to run between those positioning the phenomenon in production and those who also introduce relations outside it, mainly exchange and distribution. Probably, the concept of exploitation is usually regarded as a part of Marxist theories, but this dividing line cuts through both Marxist (e.g., G.A. Cohen 1986 and John E. Roemer 1982, respectively) and non-Marxist (e.g., P.K. Edwards 1986 and Charles Tilly 1998, respectively) analyses.

Here is an example from the non-Marxist debate: According to Edwards (1986, Ch. 2), there is a basic structured antagonism between dominating and subordinate groups in exploitative modes of production, mainly slavery, feudalism, and capitalism. The idea is that part of what is produced is used for the reproduction of what is utilized in work (machines, tools, and so on) and the workers themselves, while everything in addition to that is a surplus. For example, the capitalist can exploit the wage laborers through the latter not having any means of production and therefore have to sell or rent out their labor power in order to survive. Edwards (1986:65) sums up by saying that 'exploitation takes place by means of the labor contract.' Wage laborers are subordinate and they cannot escape this position as long as they lack alternatives. The position is structurally incumbent in the work form as such. To Edwards, this emphasis on exploitation as structured antagonism is a prerequisite of making fruitful analyses of the labor process and what happens in actually performed work-but without making it possible to draw a direct line between this structural phenomenon and employers' and wage laborers' actual patterns of behavior. (Maybe I had better point out here that it is not 
necessary to concur with Marx's theory of the value of labor to carry out the argumentation about exploitation that Edwards does.)

In Tilly's (1998) analysis, exploitation is only one-although essential-element in a general theory about inequality and its reproduction. The theory deals with durable inequality between social categories, such as men/women, employer/employee, white/ black, and citizen/foreigner, that is categorical inequality. 'Durable inequality depends heavily,' Tilly (1998:19) says, 'on the institutionalization of categorical pairs.' These categories have to be hierarchically ordered in order to create durable inequality: Men are superior to women, employers are superior to employees, whites are superior to blacks, and citizens are superior to foreigners. The categorical inequality supports exploitation-and this concept means (1998:10) that 'powerful, connected people command resources from which they draw significantly increased returns by coordinating the effort of outsiders whom they exclude from the full value added by that effort.' There are, in other words, a group of people who have established a relation with each other. This group controls a certain resource. The use of the resource can take place through work. The group can induce others to provide this effort without those others having access to the created value. This value does not have to be money but can be other material benefits or things like status, respect, or protection. This means that the concept of exploitation gets a wider area of application than in Edwards-it gets a broader social direction.

If we want to study passion and exploitation in the concrete labor process, we can thus take our point of departure in Edward's line of reasoning. That perspective on exploitation brings us straight into the labor process and the immediate activities of working people. If we, on the other hand, want to study passion and exploitation in a wider meaning, for example, when it comes to relations between work and leisure, Tilly's line of reasoning seems more appropriate, as it brings us out to more general power and inequality relations. There is, as far as I can see, no reason to choose side in this theoretical conflict in this Special Issue. By combining the two approaches, we can analyze the labor process as well as work in people's life in a wider perspective.

In the first case, we can start with the idea that working life today contains a structured antagonism between employers and wage laborers, building on the formers' exploitation of the latter. But here we have to be very careful in the analyses. These concepts are located at a structural level and specify social mechanisms, which means that they cannot say anything definite about empirical patterns in the labor process; on the other hand, we can go the opposite way, as it were, and use them as explanations of empirical patterns. Edwards (1986:58-59) also calls attention to that we have to distinguish between at least three different levels in research on workplaces and that each level has a certain autonomy from the others. The first level is the structural one, in which important concepts are exploitation and structural antagonism between dominating and dominated groups-in our case employers and employees. However, it does not determine what happens in work itself, even though it posits conditions for the next level. This is a general principle for organizing work. The main problem is to make the labor power for which the employer pays to actually perform efficient work. The third level concerns how the concrete labor process at actual workplaces functions. Here, complexity increases considerably and the conceptual set from the more abstract levels has to be nuanced.

At the highest level, structural antagonism constitutes a contradiction in a distinct meaning (Edwards 1986:68): 
A contradiction is not a logical impossibility but is a state of tension between two or more features of the social structure. This tension is not, moreover, the result of a clash between independently existing factors but stems from the very operation of the system: the operation of the economy generates forces which tend to undermine the principles on which it is based. In capitalism, for example, competition between firms tends to drive down the rate of profit, and is thus in contradiction with the need for growing profits if the process of accumulation is to continue in the long term. Similarly, unregulated capitalism requires some central co-ordination, but the development of such co-ordination through the state means that an independent body has been created which can, by influencing how the market operates, undermine the principle that markets are free of external pressure. But capitalism's most widely discussed contradiction is its tendency to bring into being a class of free wage-labourers who are tied to the capitalist only by the wage and whose potential for resistance can challenge the whole of the capitalist social structure.

Independent of whether one accepts the idea that there is a tendency for a falling rate of profit, supports a free market, or hope for a revolutionary working class, the examples provide-I think-excellent illustrations of what structural contradictions mean. The concept of contradiction is an analytical tool at the structural level and can be used as an explanation of historical trends in empirical patterns. But we cannot use it in order to predict empirical patterns or how a specific contradiction will be solved, as there always can be other and counteracting mechanisms present. In capitalist societies, the state is very influential, but it has not ruined the economy (cf. Sayer, 1995, Ch. 5); neither has the proletariat overthrown capitalism. And inversely: none of these empirical patterns mean that the contradictions do not exist. Even if a certain mechanism is counteracted by another mechanism or is not active during a certain period, it can exist.

The next level is the actual organizing of the labor process. The central problem of the dominating group, the employers, is to extract actually performed labor from the dominated group, the wage laborers. The contradiction that we can presuppose analytically is that employers rent the wage laborers' labor power, but that they must turn it into actual and efficient production. There are numerous driving forces to motivate wage laborers to make efforts. The economic coercion is favorable to the employers only in certain states of the market and it varies at each moment in time between different industries and regions. Therefore, control directly in the labor process is also necessary to make the wage laborers work hard and to receive their consent to actually using their labor power. Examples are piece rate wages, sanctions against departing from company rules, organizing teams with an in-built pressure toward efficiency, and building career ladders or propagate a company culture.

The relation between this level and the earlier one is that the employer needs to bring out the wage laborer's productive capacity within the frame of a structured antagonism. At the level of the labor process, this can have many expressions and it becomes meaningless to regard them exclusively as conflict or consent. They occur as organizational principles simultaneously, alternating, and interlaced.

Thereby, we are at the level of the actual labor process. People's real behavior is based on concrete situations and the way in which the agents interpret them. Research at this level can with advantage deal with which elements of conflict and consent that emerge in the relations of the labor process through different individuals' and groups' behavior. A basic concept comes from a now classic analysis by Wilhelm Baldamus 
(1961), namely the wage-effort bargaining: At the workplace, there are constantly formal and informal negotiations, not only about the wage and its form but also about the amount of work the employee is to perform, which quality it is to have, and which fringe benefits are to be involved. Through negotiations about relations between rewards and exertions, agreements are made at workplaces and in the local community about the quantity and quality of actually performed work. This is the concrete expression of exploitation (Edwards, 1986:73): 'the whole point of seeing production as exploitative is to escape from the view that it is a purely technical process in which amounts of labor is measurable.' What is regarded as a fair amount of work, a good day's work and its opposites, is the result of always conditioned, coarse, and variable settlements in a contradictory social context. And he adds (1986:74):

The interesting questions include how the behaviour is related to the labour process, how far it serves to alter the effort bargaining, and to what extent participants themselves see it in terms of conflict between workers and managers.

The concrete expression of the structured antagonism of exploitation is called strugglefights between employers and employees about the wage-effort bargain. Another way of expressing this is that struggle is about that aspect of actions at workplaces which concern control over the labor process. And the object of control is how the labor process is organized. To be sure, there is a double relation between employer and employee: Both are dependent upon each other, but they also have opposite desires. It follows that when we come to the level of the labor process, we must start thinking in plural: many different labor processes that all have a changing and historically conditioned 'frontier of control' (Goodrich, 1975) toward the background of the specific struggle about the relation between wages and efforts that is going on at this place. Exactly where this front is drawn varies according to different aspects of the labor processes. The concept frontier of control summarizes concretely the conditions under which actual work is performed at each specific point in time and for each aspect-that is how hired labor power is realized in work. At the same time, we do not have two pure and abstract agents, employer and employee, but multiple dividing lines within employers as well as employees. And a managing director's demands of higher bonus and a blue or white collar worker's striving for higher wages constitute in principle the same type of struggle in the wage-effort bargain of the exploitative relationship.

So far, we have looked at points of departure for analyses of passion and exploitation at workplaces. If we move outside the immediate labor process, the line of reasoning becomes different whereby we can be inspired by Tilly's argumentation about durable inequality at the societal level. He presents the essential features of a process of exploitation in this way: (1998:85-86): Exploitation is an unequal distribution of compensations in relation to the value with which the members of the organization contribute. This first thesis agrees, I think it is fair to say, with Edwards' starting point. Further, exploitation is favored by categorical inequality being established in the organization, leading to those organizations that are dependent on exploitation for their survival tending to establish categorical inequality. And finally (1998:85): 'Because organizations adopting categorical inequality deliver greater returns to their dominant members and because a portion of those returns goes to organizational maintenance, such organizations tend to crowd out other types of organizations.' 
If we were to look empirically for exploitation, Tilly's (1998:128-129) advise is that we search for seven different elements: A first is (1) power holders of some kind and (2) how they coordinate their efforts; further, there are different kinds of (3) deployable resources, (4) command over those resources, and (5) returns from them; finally which (6) categorical exclusion that is involved and how (7) the skewed division of returns is related to effort. We do not necessarily have to look for these empirical traits in that order, but we are well advised to look for them if we want to map out exploitation in a social context. One of Tilly's examples is the social development in South Africa up to the fall of apartheid (1998:117-132), so let us follow it: There were Europeans in what later came to be called South Africa already at the middle of the 15 th century. Their strength grew and gradually they started enslaving the black population. There were, however, conflicts not only between Europeans and blacks but also between the Europeans. All this was intensified when rich exploitable resources in the form of gold and diamonds (3) were discovered during the 19 th century. After many controversies, including the so-called Boer wars, a system was established in which the disposition over the resources, later complemented with industry and commerce (4), was reserved for whites-especially white capitalists-through state policy. This policy was later codified as apartheid, through which four 'races' - white, black, colored, and Indians-were constituted and assigned widely different privileges and restrictions respectively. Through this, a coalition between white higher civil servants and capitalists was established as a distinct group of power holders (1), which coordinated their strategies to exclude others from the resources (2). These resources provided considerable returns (5) in the form of net profit from mines, farms, capitalist companies, and so on. The systematic categorical exclusion of other 'races' (6) led thereby to an extremely skewed distribution of the proceeds to the advantage of those being defined as 'white' (7): The whites exploited the rest of the population.

Under the concept of exploitation, we can thus distinguish between two types of emphases, one on the labor process and the workplace as such and another on wider social contexts. Both take their point of departure in the same basic principle: structured inequality and antagonism, independent of the definition of the situation made by the involved persons. In both cases, this opens up not only for empirical studies of the concrete expressions of exploitation but also for how they are understood by those who are drawn into them.

\section{Passion and exploitation in work}

The concepts passion and exploitation may at first sight stand out as incompatible, but in principle, they can of course be related to each other (Tab. III). It is easy to make fourfold tables, but not all of them carry any theoretical weight. To start with, we can try to imagine a merging into an exploiting passion or passionate exploitation. Its direct opposite would be social contexts without both exploitation and passion. Finally, there are the possibilities of exploitation without passion and passion without exploitation, respectively.

We have already met exploiting passion in the form of workaholism and burn-out. This is the downside of passions, the subversive passions that both Fourier and modern psychology talks about. What about passionate exploitation? Perhaps one could say that the gurus of organizational fads are passionate in devoting themselves to finding new 
Table III Passion and exploitation in work

\begin{tabular}{llll}
\hline \multirow{3}{*}{ Exploitation } & & & \multicolumn{2}{c}{ Passion } \\
\hline & Yes & Yes & No \\
\cline { 2 - 4 } & & Passionate exploitation & Exploitation without passion \\
\cline { 2 - 4 } & No & Passion without exploitation & Neither passion nor exploitation \\
\hline
\end{tabular}

ways of exploiting wage laborers. Read Taylor (1998 [1911]) on Scientific Management, Hammer and Champy (1993) on Business Reengineering or Womack et al. (1990) on Lean Production and you will see what I mean.

When we come to exploitation without passion, we have to leave the sphere of human agents and go to social structures and social systems. Capitalism can in itself not feel passion-social structures do not have emotions-but it is an exploitative economic system as I have discussed above. To find passion without exploitation, we have to get back into the human sphere, into the emotions of people, and here I suggest that such people can be found in the social category of self-employed without employees-at least to the extent that they are not self-exploiting and thereby suffer obsessive passions. If they have employees, they are a part of capitalism and are per definition exploiters of others. The last outcome of the fourfold table, in which there is neither passion nor exploitation, is of little interest at the moment.

\section{References}

Applebaum, H. (1984) 'Theoretical introduction', in Herbert Applebaum (ed.) Work in Market and Industrial Societies. Albany: State University of New York Press.

Asplund, J. (1979) Teorier om framtiden. [Theories about the Future] Stockholm: Liber.

Baldamus, W. (1961) Efficiency and Effort: An Analysis of Industrial Administration. London: Tavistock.

Bertrand, J. (2009) 'Entre 'passion' et incertitude: La socialisation du métier de footballeur professionnel.' Sociologie du travail, 51(3): 361-78.

Bolton, S.C. (2007) (ed.) Dimensions of Dignity at Work. Amsterdam: Butterworth-Heinemann.

Brodsky, W. (2006) 'In the wings of British orchestras: a multi-episode interview study among symphony players.' Journal of Occupational and Organizational Psychology, 79(4): 673-90.

Cardon, M.S., J. Wincent, J. Singh and M. Drnovsek (2009) 'The nature and experience of entrepreneurial passion.' Academy of Management Review, 34(3): 511-23.

Cohen, G.A. (1978) Karl Marx's Theory of History. A Defence. Oxford: Oxford University Press.

Daniels, A.K. (1987) 'Invisible work.' Social Problems, 34(3): 403-15.

Dubin, R. (1965) The World of Work. Englewood Cliffs: Prentice-Hall.

Edwards, P.K. (1986) Conflict at Work. A Materialist Analysis of Workplace Relations. London: Basil Blackwell.

Fourier, C. (1966-68) Cuvres completes. (12 Vols. ed. Simone Debout-Olezkiewicz) Paris: Édition Anthropos. 
Fourier, C. (1968 [1851]) The Passions of the Human Soul and Their Influence on Society and Civilization. Two Volumes. New York: Kelley.

Goodrich, C.L. (1975 [1920]) The Frontier of Control. London: Pluto.

Gubman, E. (2004) 'From Engagement to Passion for Work: The Search for the Missing Person.' Human Resource Planning 27(3): 42-46.

Hammer, M. and J. Champy (1993) Reengineering the Corporation: A Manifesto for Business Revolution. New York: Harper.

Hobsbawm, E. (2011) How to Change the World. London: Abacus.

Houlfort, N. and R.J. Vallerand (2006) 'Le passion envers le travail: les deux côtés de la médaille.' Revue multidisciplinaire sur l'emploi, le syndicalisme et le travail, 2(1): 4-17.

Karlsson, J.Ch. (2004) 'The Ontology of Work: Social Relations and Doing in the Sphere of Necessity', pp. 90-112 in Steve Fleetwood \& Stephen Ackroyd (eds) Critical Realist Applications in Organisation and Management Studies. London: Routledge.

Karlsson, J.Ch. (2011) 'Arbete, passion och exploatering,' pp. 7-22 in Tuula Bergqvist, Gunnar Gillberg \& Lars Ivarsson (eds) Arbete: passion and exploatering. [Work: Passion and Exploitation] Växjö: Arbetsliv i Omvandling.

Karlsson, J.Ch. (2013) Begreppet arbete. [The Concept of Work] Lund: Arkiv.

Kosík, K. (1976) Dialectics of the Concrete. Dordrecht: D. Riedel.

Marshall, A. (1907 [1890]) Principles of Economics. London: Macmillan.

Nielsen, K. and R. Ware (1997) Exploitation. Atlantic Highlands, N. J.: Humanities Press.

Parker, M., V. Fournier and P. Reedy (2007) The Dictionary of Alternatives. Utopianism o Organization. London: Zed.

Roemer, J.E. (1982) A General Theory of Exploitation and Class. Cambridge: Harvard University Press.

Sayer, A. (1995) Radical Political Economy. A Critique. Oxford: Blackwell.

Shelby, T. (2002) 'Parasites, Pimps, and Capitalists: A Naturalistic Conception of Exploitation.' Social Theory and Practice, 28(3): 381-418.

Taylor, F.W. (1998 [1911]) The Principles of Scientific Management. Atlanta: Engineering \& Management Press.

Tilly, C. (1998) Durable Inequality. Berkeley, Cal.: University of California Press.

Vallerand, R.J., C. Blanchard, G.A. Mageau, R. Koestner, C. Ratelle, M. Léonard, M. Gagné and J. Marsolais (2003) 'Les Passions de l'Âme: On Obsessive and Harmonious Passion.' Journal of Personality and Social Psychology, 85(4): 756-67.

Wadel, C. (1979) 'The Hidden Work of Everyday Life,' in Sandra Wallman (ed.) Social Anthropology of Work. London: Academic Press.

Weber, M. (1978) Economy and Society. An Outline of Interpretive Sociology. (Ed. Guenther Roth \& Claus Wittich) Berkeley, Cal.: University of California Press.

Womack, J.P., D.T. Jones and D. Ross (1990) The Machine that Changed the World. New York: Rawson. 